\title{
CONHECIMENTO DE PUÉRPERAS SOBRE AMAMENTAÇÃO E INTRODUÇÃO ALIMENTAR
}

\section{Postpartum women's knowledge about breastfeeding and introduction of other foods \\ Conocimiento de puérperas sobre amamantamiento e introducción alimentaria}

\author{
Juliana de Brito de Souza Rosa \\ Universidade Luterana do Brasil - ULBRA - Canoas (RS) - Brasil \\ Susana Elena Delgado \\ Universidade Luterana do Brasil - ULBRA - Canoas (RS) - Brasil
}

\section{RESUMO}

Objetivo: Verificar o conhecimento materno sobre amamentação e introdução alimentar e identificar as dificuldades de aleitamento no alojamento conjunto de um hospital universitário. Métodos: Estudo quantitativo, observacional e transversal, realizado em 2016, em Canoas, Rio Grande do Sul, com amostra de 40 binômios mãe-bebê internados em alojamento conjunto de um hospital universitário. Utilizou-se protocolo adaptado do Fundo das Nações Unidas para a Infância para avaliar os comportamentos favoráveis e desfavoráveis durante a amamentação por meio de entrevista contendo: dados sociodemográficos; tipo de parto; idade gestacional e peso do bebê; conhecimento sobre amamentação exclusiva e seus benefícios; idade da introdução alimentar e tipos de alimento. Utilizou-se estatística descritiva e associação entre as variáveis. Resultados: A frequência de dificuldades na amamentação variou entre $5 \%$ e $45 \%$ conforme o aspecto avaliado. As escoriações do tecido mamário associaram-se com bebê que não mantém a pega, sucções rápidas com estalidos e lábio inferior virado para dentro $(\mathrm{p}<0,05)$ na amamentação. Sobre o conhecimento, $65 \%(\mathrm{n}=26)$ desconheciam os benefícios da amamentação para a mãe, $88 \%(\mathrm{n}=35)$ citaram o crescimento e 75\% (30), a imunidade e o vínculo como benefícios para o filho; $45 \%$ ( $\mathrm{n}=18)$ não sabiam definir aleitamento exclusivo e $95 \%(n=18)$ citaram que a introdução da alimentação complementar deveria ocorrer após os 6 meses. Conclusão: As mães investigadas possuem conhecimento limitado sobre amamentação, desconhecem os benefícios para a saúde da mulher, porém citaram benefícios em relação aos filhos. Observaram-se aspectos desfavoráveis no momento da amamentação.

Descritores: Alojamento Conjunto; Aleitamento Materno; Nutrição da Criança.

\section{ABSTRACT}

Objective: To assess mothers' knowledge about breastfeeding and introduction of other foods and identify the difficulties in breastfeeding in the rooming-in ward of a university hospital. Methods: Quantitative observational cross-sectional study carried out in 2016 in Canoas, Rio Grande do Sul, with a sample of 40 mother-baby binomials admitted to the rooming-in ward of a university hospital. A protocol adapted from the United Nations Children's Fund was used to assess favorable and unfavorable behaviors during breastfeeding through interviews addressing: sociodemographic information, type of delivery, gestational age, weight of the baby, knowledge about exclusive breastfeeding and its benefits, age at the time of introduction of other foods, and the types of foods introduced. Descriptive statistics was used and associations between variables were assessed. Results: The frequency of difficulties in breastfeeding ranged from 5\% to $45 \%$ according to the aspect assessed. Breast tissue excoriations were associated with baby's difficulty in maintaining the latch, fast sucking with clicking noises and bottom lip turned inwards $(p<0.05)$. With regard to knowledge, $65 \%(n=26)$ of the participants did not know how they benefited from breastfeeding. Additionally, $88 \%(n=35)$ reported growth and $75 \%(30)$ reported immunity and bonding as the main benefits to the baby. In all, $45 \%(n=18)$ of the mothers could not define exclusive breastfeeding and $95 \%(n=18)$ said that complementary feeding should be started after 6 months of life. Conclusion: The mothers interviewed have poor knowledge about breastfeeding and do not know the benefits to women's health. However, they reported the benefits to the baby. Unfavorable aspects were evident during breastfeeding.

Descriptors: Roooming-in Care; Breast Feeding; Child Nutrition. 


\section{RESUMEN}

Objetivo: Verificar el conocimiento materno sobre el amamantamiento y la introducción alimentaria e identificar las dificultades de la lactancia materna en el alojamiento conjunto de un hospital universitario. Métodos: Estudio cuantitativo, observacional y transversal realizado en 2016, en Canoas, Rio Grande de Sul con una muestra de 40 binomios madre-bebé ingresados en el alojamiento conjunto de un hospital universitario. Se utilizó un protocolo adaptado del Fondo de las Naciones Unidas para la Infancia para evaluar las conductas favorables y desfavorables durante el amamantamiento a través de la entrevista con los datos sociodemográficos; el tipo de parto; la edad gestacional y el peso del bebé; el conocimiento del amamantamiento exclusivo y sus beneficios; la edad de la introducción alimentaria y los tipos de alimento. Se utilizó la estadística descriptiva y la asociación entre las variables. Resultados: La frecuencia de dificultades para el amamantamiento varió entre el 5\% y el 45\% según el aspecto evaluado. Las escoriaciones del tejido mamario se asociaron con el bebé que no tiene la pega, las succiones rápidas con los crujidos y el labio inferior girado para dentro $(p<0,05)$ en el amamantamiento. Sobre el conocimiento, el 65\% (n=26) desconocían los beneficios del amamantamiento para la madre, el 88\% (n=35) citaron el crecimiento y el $75 \%$ (30) la inmunidad y el vínculo como los beneficios para el hijo; el 45\% (n=18) no sabian definir la lactancia materna exclusiva y el 95\% (n=18) citaron que la introducción de la alimentación complementaria debería se da después de los 6 meses. Conclusión: Las madres investigadas tienen conocimiento limitado sobre el amamantamiento, desconocen los beneficios para la salud de la mujer, sin embargo, han citado los beneficios respecto los hijos. Se observaron aspectos desfavorables durante el amamantamiento.

Descriptores: Alojamiento Conjunto; Lactancia Materna; Nutrición del Niño.

\section{INTRODUÇÃO}

O aleitamento materno é um grande e importante acontecimento nos primeiros meses de vida do bebê. Através dele consegue-se suprir todas as necessidades nutritivas do recém-nascido, além de reforçar o aumento de anticorpos, ganho de peso, propiciar maior vínculo entre mãe e filho, e promover o desenvolvimento das estruturas orais, que são responsáveis pelo funcionamento adequado da respiração, da suç̧ão, da deglutição, da mastigação e da fala ${ }^{(1)}$.

O alojamento conjunto é um sistema hospitalar em que o recém-nascido sadio permanece ao lado da mãe até a alta ${ }^{(2)}$. Tem por objetivo a integração mãe-bebê, contribuindo para o incentivo do aleitamento materno, orientações de cuidado da mãe com o bebê e a prevenção de infecções ${ }^{(3)}$.

Destaca-se a importância do conhecimento das mães sobre aleitamento materno, conhecimento que interfere diretamente na decisão da mãe em amamentar ou não o seu filho e a duração da mesma. Sabe-se também que a maioria das dificuldades apresentadas durante o período de lactação, quando precocemente tratadas, são de fácil solução e têm como resultado experiências satisfatórias tanto para a mãe quanto para o bebê( ${ }^{(4)}$.

As principais dificuldades encontradas no início do aleitamento materno referem-se à posição inadequada, que dificulta a pega correta, podendo causar traumas mamilares, mamadas pouco eficientes e o não esvaziamento completo das mamas, que, consequentemente, resultam de maneira negativa na produção de leite, interferindo no crescimento dos bebês ${ }^{(5)}$.

O Ministério da Saúde, juntamente com a Organização Mundial da Saúde, recomenda que o aleitamento materno seja feito de maneira exclusiva até o sexto mês de vida do bebê. A partir dessa idade deve ser complementado até os dois anos ${ }^{(6)}$. A correta introdução alimentar é tão importante quanto o aleitamento materno, devendo ser introduzidos alimentos variados de consistência pastosa e sólida, de maneira lenta e gradual ${ }^{(7,8)}$.

Dessa forma, o aleitamento materno, seguido por uma adequada introdução alimentar dos bebês, é importante para que haja um apropriado crescimento e desenvolvimento das crianças, especialmente nos dois primeiros anos de vida. Assim, justifica-se investigar as dificuldades e o conhecimento das mães sobre essas questões para qualificar as orientações sobre o aleitamento materno e a introdução alimentar, auxiliando na qualidade de vida das crianças.

Portanto, este estudo tem por objetivo verificar o conhecimento materno sobre amamentação e introdução alimentar e identificar as dificuldades de aleitamento no alojamento conjunto de um hospital universitário.

\section{MÉTODOS}

Trata-se de um estudo quantitativo, observacional e transversal, realizado no período de maio a agosto de 2016, no alojamento conjunto do Hospital Universitário Ulbra - Mãe de Deus, em Canoas, Rio Grande do Sul, Brasil.

A amostra de conveniência foi constituída por 40 binômios mães/recém-nascido. Incluíram-se mulheres entre 15 e 46 anos, internadas durante o período da pesquisa e que estavam amamentando. Excluíram-se as mães que não concordaram em assinar o Termo de Consentimento Livre Esclarecido. As mães com idade inferior a 18 anos assinaram um termo de assentimento e os seus responsáveis assinaram o Termo de Consentimento Livre e Esclarecido.

Realizou-se entrevista com as mães para coletar dados referentes a ela e ao bebê, relacionado a informações sociodemográficas, tipo de parto, idade gestacional e peso do bebê. Foram realizadas quatro perguntas abertas a respeito do 
conhecimento das puérperas sobre amamentação exclusiva, seus benefícios e a idade da introdução alimentar, como também sobre quais alimentos devem ser introduzidos conforme a idade do bebê.

Em seguida, observou-se a mamada conforme protocolo adaptado ${ }^{(5)}$. Foram observados comportamentos favoráveis e desfavoráveis da mãe e do neonato durante a amamentação, referentes a dificuldades no início do aleitamento materno no alojamento conjunto. Para estabelecer o desempenho da mamada, foram avaliados a posição mãe/bebê, respostas da dupla, adequação da sucção, anatomia das mamas e estabelecimento de laços afetivos entre a dupla, classificando-a como boa, regular ou ruim, conforme os escores apresentados no Quadro I. Além disso, após a pesquisa, as mães receberam orientação e folder informativo.

Quadro I - Critérios para classificação dos escores na avaliação da mamada segundo aspecto avaliado.

\begin{tabular}{|c|c|c|c|c|}
\hline \multirow[t]{2}{*}{ Aspectos avaliados } & \multirow[t]{2}{*}{ Comportamentos negativos investigados } & \multicolumn{3}{|c|}{$\begin{array}{l}\text { Número de comportamentos negativos } \\
\text { observados / Classificação dos escores }\end{array}$} \\
\hline & & Bom & Regular & Ruim \\
\hline Posição mãe/criança & $\begin{array}{l}\text { Mãe com ombros tensos e inclinada sobre o bebê } \\
\text { Corpo do bebê distante do da mãe } \\
\text { O bebê está com o pescoço virado } \\
\text { O queixo do bebê não toca o peito } \\
\text { Só ombros/cabeça apoiados }\end{array}$ & $0-1$ & $2-3$ & $4-5$ \\
\hline Respostas dupla & $\begin{array}{l}\text { Nenhuma resposta ao peito } \\
\text { Nenhuma busca observada } \\
\text { O bebê não está interessado no peito } \\
\text { Bebê irrequieto ou chorando } \\
\text { O bebê não mantém a pega da aréola } \\
\text { Nenhum sinal de ejeção de leite }\end{array}$ & $0-1$ & $2-3$ & $4-6$ \\
\hline Adequação da sucção & $\begin{array}{l}\text { Boca quase fechada } \\
\text { Lábio inferior virado para dentro } \\
\text { Não se vê a língua do bebê } \\
\text { Bochechas tensas ou evocadas } \\
\text { Sucções rápidas com estalidos } \\
\text { Pode-se ouvir barulhos altos, mas não a deglutição }\end{array}$ & $0-1$ & $2-3$ & $4-6$ \\
\hline Anatomia das mamas & $\begin{array}{l}\text { Mamas ingurgitadas e duras } \\
\text { Mamilos planos ou invertidos } \\
\text { Tecido mamário com escoriações } \\
\text { Mamas esticadas ou caídas }\end{array}$ & 0 & 1 & $2-4$ \\
\hline Afetividade & $\begin{array}{l}\text { Mãe segura o bebê nervosamente } \\
\text { Nenhum contato ocular mãe/filho } \\
\text { Mãe e bebê quase não se tocam }\end{array}$ & 0 & 1 & $2-3$ \\
\hline
\end{tabular}

Fonte: Carvalhães et al., 2003(5)

Os dados foram armazenados em um banco de dados e sofreram análise estatística descritiva para expor os resultados obtidos através do instrumento de coleta e aplicou-se o teste qui-quadrado para análise da associação significativa entre as variáveis estudadas, sendo considerados significativos valores de "p" menor ou igual a 0,05 . A apresentação das variáveis mensuradas ocorreu através de tabelas.

Esta pesquisa recebeu aprovação pelo Comitê de Ética em Pesquisa da Universidade Luterana do Brasil, em Canoas, Rio Grande do Sul, sob Parecer n 1046688.

\section{RESULTADOS}

A população em estudo foi composta por 40 puérperas, internadas na maternidade. A idade das mães variou entre 15 a 46 anos, com média de 26 anos. Das mães entrevistadas, 32,5\% ( $\mathrm{n}=13)$ possuíam ensino médio completo, 77,5\% ( $\mathrm{n}=31)$ moravam com o companheiro e $85 \%(n=34)$ realizaram ao menos 6 consultas de pré-natal. As mães que realizaram pré-natal afirmaram não ter recebido qualquer informação sobre aleitamento materno durante as consultas. No que diz respeito à gestação, $40 \%$ 
$(\mathrm{n}=16)$ eram primíparas e $72,5 \%(\mathrm{n}=29)$ tiveram parto normal. Em relação à amamentação, 55\% $(\mathrm{n}=22)$, já haviam amamentado antes e $35 \%(n=14)$ das mães relataram não sentir dificuldades para amamentar (Tabela I).

Tabela I - Caracterização do binômio mãe/filho de um alojamento conjunto do Hospital Universitário Ulbra/Mãe de Deus, em Canoas, Rio Grande do Sul, 2016.

\begin{tabular}{|c|c|c|}
\hline Variáveis & $\mathbf{n}$ & $\%$ \\
\hline \multicolumn{3}{|l|}{ Escolaridade } \\
\hline Ensino fund. incompleto & 13 & $32,5 \%$ \\
\hline Ensino fund. & 3 & $7,5 \%$ \\
\hline Ensino méd. incompleto & 9 & $22,5 \%$ \\
\hline Ensino méd. & 13 & $32,5 \%$ \\
\hline Ensino sup. incompleto & 2 & $5,0 \%$ \\
\hline Ensino sup. & 0 & $0,0 \%$ \\
\hline \multicolumn{3}{|l|}{ Renda familiar } \\
\hline Sem renda & 2 & $5,0 \%$ \\
\hline Um a três salários mínimos & 33 & $82,5 \%$ \\
\hline Quatro a seis salários mínimos & 5 & $12,5 \%$ \\
\hline Mais de seis salários mínimos & 0 & $0,0 \%$ \\
\hline \multicolumn{3}{|l|}{ Mora com o companheiro } \\
\hline Sim & 31 & $77,5 \%$ \\
\hline Não & 9 & $22,5 \%$ \\
\hline \multicolumn{3}{|l|}{ Tipo de parto } \\
\hline Vaginal & 29 & $72,5 \%$ \\
\hline Cesárea & 11 & $27,5 \%$ \\
\hline \multicolumn{3}{|l|}{ Já amamentou antes deste bebê? } \\
\hline Sim & 22 & $55,0 \%$ \\
\hline Não & 18 & $45,0 \%$ \\
\hline \multicolumn{3}{|c|}{ Está com dificuldades para amentar? } \\
\hline Sim & 14 & $35,0 \%$ \\
\hline Não & 26 & $65,0 \%$ \\
\hline \multicolumn{3}{|l|}{ Fez pré-natal? } \\
\hline Sim & 34 & $85,0 \%$ \\
\hline Não & 6 & $15,0 \%$ \\
\hline
\end{tabular}

Fund: Fundamental; Méd: médio; Sup: superior

Os recém-nascidos tinham entre 2 a 13 dias de vida e apresentaram, ao serem admitidos no alojamento conjunto, idade gestacional de 36 a 42 semanas, com média de 39 semanas (desvio padrão de 1,3), e apenas um era prematuro (limítrofe). O peso médio foi $3,28 \mathrm{~kg}$, com desvio padrão de $0,44 \mathrm{~kg}$.

Conforme os escores do protocolo de avaliação dos comportamentos do binômio mãe/bebê na mamada, observou-se que de $48 \%$ a $75 \%$ dos binômios apresentou indicativos de início satisfatório da amamentação, a depender do critério avaliado. Porém, observou-se a ocorrência de diversos comportamentos sugestivos de dificuldades em todos os aspectos analisados (Tabela II).

Tabela II - Distribuição (\%) das duplas mãe/recém-nascido de acordo com os escores relativos à posição corporal, respostas do binômio, afetividade, anatomia das mamas e sucção no Hospital Ulbra/Mãe de Deus, em Canoas, Rio Grande do Sul, 2016.

\begin{tabular}{lccc}
\hline Aspectos & Bom & $\begin{array}{c}\text { Classificação dos escores } \\
\text { Regular }\end{array}$ & Ruim \\
\hline Posição & $70 \%$ & $25 \%$ & $5 \%$ \\
Respostas & $75 \%$ & $25 \%$ & $0 \%$ \\
Laços afetivos & $63 \%$ & $25 \%$ & $13 \%$ \\
Anatomia das mamas & $48 \%$ & $38 \%$ & $15 \%$ \\
Sucção & $58 \%$ & $18 \%$ & $25 \%$ \\
\hline
\end{tabular}

Os aspectos com maior número de comportamentos indicativos de dificuldades no início do aleitamento materno foram: anatomia das mamas, sucção e estabelecimento de laços afetivos (Tabela III). No aspecto de anatomia das mamas, observou-se que $45 \%(n=18)$ das mães apresentavam tecido mamário com escoriações, fissuras e vermelhidão, e $13 \%$ (n=5) tinham mamilos planos ou invertidos. 
Tabela III - Classificação das dificuldades iniciais do aleitamento materno no alojamento conjunto do Hospital Universitário Ulbra/Mãe de Deus, em Canoas, Rio Grande do Sul, 2016.

\begin{tabular}{|c|c|c|c|}
\hline Aspectos & Comportamentos negativos investigados & $\mathbf{n}$ & $\%$ \\
\hline \multicolumn{4}{|l|}{ Posição } \\
\hline & Mãe com ombros tensos e inclinada sobre o bebê & 10 & $25 \%$ \\
\hline & Corpo do bebê distante do da mãe & 12 & $30 \%$ \\
\hline & O bebê está com o pescoço virado & 11 & $28 \%$ \\
\hline & O queixo do bebê não toca o peito & 5 & $13 \%$ \\
\hline & Só ombros/Cabeça apoiados & 2 & $5 \%$ \\
\hline \multicolumn{4}{|c|}{ Respostas } \\
\hline & Nenhuma resposta ao peito & 1 & $3 \%$ \\
\hline & Nenhuma busca observada & 1 & $3 \%$ \\
\hline & O bebê não está interessado no peito & 1 & $3 \%$ \\
\hline & Bebê irriquieto ou chorando & 10 & $25 \%$ \\
\hline & O bebê não mantém a pega da aréola & 15 & $38 \%$ \\
\hline & Nenhum sinal de ejeção de leite & 1 & $3 \%$ \\
\hline \multicolumn{4}{|c|}{ Laços afetivos } \\
\hline & Mãe segura o bebê nervosamente & 7 & $18 \%$ \\
\hline & Nenhum contato ocular mãe/ filho & 6 & $15 \%$ \\
\hline & Mãe e bebê quase não se tocam & 12 & $30 \%$ \\
\hline \multicolumn{4}{|c|}{ Anatomia das mamas } \\
\hline & Mamas ingurgitadas e duras & 2 & $5 \%$ \\
\hline & Mamilos planos ou invertidos & 5 & $13 \%$ \\
\hline & Tecido mamário com escoriações & 18 & $45 \%$ \\
\hline & Mamas esticadas ou caídas & 4 & $10 \%$ \\
\hline \multicolumn{4}{|l|}{ Sucção } \\
\hline & Boca quase fechada & 11 & $28 \%$ \\
\hline & Lábio inferior virado para dentro & 16 & $40 \%$ \\
\hline & Não se vê a língua do bebê & 7 & $18 \%$ \\
\hline & Bochechas tensas ou encovadas & 6 & $15 \%$ \\
\hline & Sucções rápidas com estalidos & 12 & $30 \%$ \\
\hline & Pode-se ouvir barulhos altos, mas não a deglutição & 9 & $23 \%$ \\
\hline
\end{tabular}

*Respostas múltiplas

Com referência ao aspecto de sucção do bebê, $40 \%(\mathrm{n}=16)$ apresentaram lábio inferior virado para dentro durante a mamada, $30 \%(n=12)$ mantinham sucções rápidas com estalidos e 28\% $(n=11)$ não tinham a boca bem aberta para realizar a pega.

Em relação ao aspecto dos laços afetivos, foram encontrados frequentes comportamentos de dificuldade, sendo que $30 \%$ $(n=12)$ das mães quase não tocavam os bebês, $18 \%(n=7)$ das mães seguravam o bebê nervosamente e $15 \%(n=6)$ não mantinham contato visual com os bebês.

Quando se correlacionou as escoriações do tecido mamário com o bebê não manter a pega da aréola, apresentar suç̧ões rápidas com estalidos e/ou lábio inferior virado para dentro, pode-se afirmar que as correlações são significativas, pois apresentaram valor de $\mathrm{p}<0,05$ (Tabela IV).

Tabela IV - Associação entre as dificuldades da amamentação e tecido mamário com escoriações no alojamento conjunto do Hospital Universitário Ulbra/Mãe de Deus, em Canoas, Rio Grande do Sul, 2016.

\begin{tabular}{|c|c|c|c|c|c|}
\hline \multirow[t]{3}{*}{ Variáveis } & \multicolumn{5}{|c|}{ Tecido mamário com escoriações } \\
\hline & & & & ăo & \\
\hline & $\mathbf{n}$ & $\%$ & n & $\%$ & $p^{*}$ \\
\hline \multicolumn{6}{|c|}{ Bebê mantém a pega da aréola } \\
\hline Sim & 6 & $33 \%$ & 19 & $86 \%$ & \multirow{3}{*}{0,002} \\
\hline Não & 12 & $67 \%$ & 3 & $14 \%$ & \\
\hline Total & 18 & $100 \%$ & 22 & $100 \%$ & \\
\hline \multicolumn{6}{|c|}{ Sucções rápidas com estalidos } \\
\hline Sim & 9 & $50 \%$ & 3 & $14 \%$ & \multirow{3}{*}{0,032} \\
\hline Não & 9 & $50 \%$ & 19 & $86 \%$ & \\
\hline Total & 18 & $100 \%$ & 22 & $100 \%$ & \\
\hline \multicolumn{6}{|c|}{ Lábio inferior virado para dentro } \\
\hline Sim & 14 & $78 \%$ & 2 & $9 \%$ & \multirow[t]{3}{*}{0,000044} \\
\hline Não & 4 & $22 \%$ & 20 & $91 \%$ & \\
\hline Total & 18 & $100 \%$ & 22 & $100 \%$ & \\
\hline
\end{tabular}

${ }^{*}$ Teste qui-quadrado 
Nas questões abertas, após analise de conteúdo, foram categorizados os seguintes aspectos: quando questionadas sobre os benefícios do aleitamento materno para elas, 26 (65\%) das mães não souberam responder. Das que responderam, $12(30 \%)$ mães referiram a perda de peso como único beneficio. Já no que se refere aos benefícios para os bebês, foram explicitados 3 aspectos: 35 (88\%) mães citaram o crescimento, 30 (75\%) citaram a imunidade e vínculo, sendo esse último apenas citado por 2 mães, e houve ainda uma mãe que afirmou não trazer benefícios para mãe ou bebê.

Com respeito ao conhecimento materno sobre aleitamento materno exclusivo e sua duração, 18 mães (45\%) não souberam responder e 14 mães (35\%) têm o conhecimento de que não deve ser feita a oferta de água/chás e/ou outros alimentos durante o aleitamento materno exclusivo e que deve ser realizado até o bebê completar seis meses de vida.

Em relação ao conhecimento materno sobre a idade adequada para introdução alimentar, 38 (95\%) mães citaram que deve ser feita após seis meses de vida do bebê, porém 12 (30\%) delas irão introduzir alimentação complementar aos 4 meses devido à volta ao trabalho.

No que diz respeito aos tipos de alimento que devem ser introduzidos na alimentação dos bebês, 23 (58\%) mães referiram que devem ser introduzidas papas doces (frutas) e salgadas (legumes) após o bebê completar seis meses (porém três dessas mães referem que as papas serão liquidificadas); 33 mães (82,5\%) relataram que até completar 1 ano de vida os bebês já estariam inseridos na dieta da família; 2 (5\%) mães referiram que só fariam a introdução da alimentação complementar após os bebês complementarem 1 ano de idade; 5 mães (12,5\%) só fariam oferta de carnes e grãos após os 18 os meses, e 5 mães $(12,5 \%)$ ofereceriam iogurtes e papas industrializadas antes de 1 ano de idade.

\section{DISCUSSÃO}

Nos últimos anos, apesar de se ter observado um aumento nas taxas de aleitamento materno no Brasil, ainda não foi atingido o que a Organização Mundial da Saúde preconiza. Algumas questões, como fatores biológicos, culturais, relativos à atenção à saúde e socioeconômicos, além de atitudes e práticas de profissionais da saúde, influenciam diretamente na manutenção correta do aleitamento materno exclusivo ${ }^{(9)}$.

No presente estudo foram observadas e avaliadas as principais dificuldades da amamentação no alojamento conjunto, assim como o conhecimento das mães sobre aleitamento materno e a introdução alimentar complementar.

A média de idade das mães do presente estudo foi de 26 anos, semelhante a outro estudo ${ }^{(10)}$, em que a média de idade foi de 25,7 anos. Além disso, 77,5\% dessas mulheres viviam com o companheiro, assim como encontrado em outro estudo, em que $72 \%$ da amostra era de mulheres casadas ou que viviam com o companheiro, fator que pode ser considerado importante, pois a presença do companheiro oferece suporte emocional à mulher nesse período ${ }^{(11)}$.

A Portaria $n^{\circ} 1.067$ de 4 de julho de $2005^{(12)}$ garante à gestante, durante as consultas de pré-natal, orientação e incentivo para o aleitamento materno e orientação específica para as que não poderão amamentar, contudo $85 \%$ das mães que participaram da atual pesquisa e realizaram o pré-natal afirmaram não terem recebido qualquer informação durante a gestação, resultado diferente ao encontrado em outro estudo ${ }^{(13)}$, em que a minoria das entrevistadas que realizaram pré-natal alegaram não ter recebido alguma orientação referente à amamentação durante esse período.

As orientações sobre a amamentação devem ter início no pré-natal e deve ser dada continuidade no pós-natal, principalmente nos primeiros dias de vida do bebê, com intuito de corrigir ideias errôneas a respeito do aleitamento materno ${ }^{(14)}$. Estudo mostra que os profissionais abordam as questões do aleitamento materno com as mulheres durante alguns atendimentos, entretanto essa não é uma rotina praticada em todos os atendimentos nem por todos os profissionais ${ }^{(15)}$.

As dificuldades mais frequentes na amamentação observadas na presente investigação foram no aspecto sucção, como encontrado também em outro estudo ${ }^{(16)}$, em que os comportamentos indicativos de dificuldade foram lábio inferior virado para dentro, sucções rápidas com estalidos e boca quase fechada. Esses fatores podem acarretar em mamadas pouco eficientes, deixando os bebês insatisfeitos e, consequentemente, apresentarem-se irrequietos e/ou chorando.

Também se observaram no presente estudo comportamentos indicativos de dificuldade no que diz respeito à posição da mãe e do bebê durante a mamada, sendo os mais frequentes: bebê com o corpo distante da mãe; mãe com ombros tensos e inclinados sobre o bebê; e bebê com o pescoço virado. Tais comportamentos tendem a dificultar a pega adequada, podendo causar traumas mamilares, que se constituem numa das causas do desmame precoce ${ }^{(5)}$.

Observou-se correlação significativa na pesquisa em questão entre a variável tecido mamário com escoriações, fissuras e vermelhidão e o bebê não manter a pega da aréola, suç̧ões rápidas com estalidos e lábio inferior virado para dentro. Todos esses aspectos referem-se à pega inadequada. Portanto, o conhecimento sobre a correta técnica de amamentação fazse imprescindível, visto que o posicionamento adequado da dupla e a pega efetiva do bebê favorecem a prevenção de dor ao amamentar e traumas mamilares, reduzindo a probabilidade de interrupção do aleitamento materno por complicações ${ }^{(17)}$.

Em relação à anatomia das mamas, detectou-se que $52 \%$ das mães da presente pesquisa apresentavam escores entre regular e ruim, dado que corrobora outro estudo ${ }^{(18)}$, no qual $56 \%$ das mães apresentaram escores entre regular ou ruim, sendo que, em ambos os estudos, a maior dificuldade apresentada foi tecido mamário com escoriações, fato que pode ser explicado pela falta de conhecimento sobre a técnica correta de amamentação. 
Com relação aos comportamentos indicativos de afetividade, $38 \%$ da amostra da atual pesquisa apresentou respostas negativas, e outro estudo ${ }^{(5)}$ apresentou resultado semelhante, no qual 34\% das duplas obtiveram escores regular e/ou ruim, o que pode ser explicado pelo fato de, no período pós-parto, as mães apresentarem-se mais sensíveis e suscetíveis quanto à sua capacidade de amamentar ${ }^{(11)}$.

O aleitamento materno exclusivo nos primeiros 6 meses de vida do bebê é de suma importância, pois garante nutrição adequada, ajuda no desenvolvimento das estruturas orais, como lábios, língua, bochechas, palato duro e mole, responsáveis pelo funcionamento adequado das funções de respiração, sucção, mastigação, deglutição e fonoarticulação, além de propiciar o padrão de respiração nasal ${ }^{(16)}$. Contudo, no presente estudo, grande parcela das mães desconhece o significado de aleitamento materno exclusivo. As que souberam responder, relataram que deve ser realizada até o sexto mês de vida a oferta apenas do leite materno, porém uma parcela dessas mães referiu sentir a necessidade de fazer oferta de outros líquidos, como água e chás, a fim de saciar a sede dos bebês, cujo fator pode estar associado à crenças e mitos sobre amamentação. Os chás e água são contraindicados, pois podem levar a saciedade, diminuindo a ingestão de leite materno e acarretando em déficit calórico ${ }^{(19)}$.

Quando questionadas sobre os benefícios do aleitamento materno para os bebês, a maior parte das mães entrevistadas no presente estudo citaram o crescimento, ganho de peso e imunidade, dado também encontrado em outros estudos ${ }^{(13,20)}$. Mesmo com a falta de informação recebida durante o pré-natal, pode-se perceber que as mães apresentam conhecimentos a respeito do aleitamento materno, o que pode ser explicado pelo maior nível de informação fornecido pelas mídias sociais e pela grande ênfase relacionada aos benefícios do aleitamento materno para os bebês em campanhas nacionais ${ }^{(6)}$.

A maioria das entrevistadas no atual estudo acreditava que a amamentação trazia benefícios apenas para os bebês, resultado semelhante foi encontrado em outro estudo ${ }^{(21)}$. As mães que referiram que o aleitamento materno traz benefícios para a mulher, citaram a perda de peso no pós-parto como principal benefício, dado também encontrado em outro estudo ${ }^{(22)}$. Este aspecto que pode ser explicado pela falta de orientação durante o pré-natal e também pelo fato de as mulheres sentirem-se cobradas pela sociedade sobre o aleitamento materno, entendendo que essa prática deve ser uma obrigação materna e não uma escolha consciente e benéfica para o binômio mãe/bebê $\hat{~}^{(6)}$.

Grande parte das mães (95\%) entrevistadas na atual pesquisa tinha o conhecimento de que o aleitamento materno exclusivo deve ser realizado até o sexto mês do bebê, porém uma parcela delas (30\%) relatou a necessidade de introduzir outros alimentos precocemente devido à volta ao trabalho. Uma revisão de literatura ${ }^{(23)}$ verificou que a falta de apoio nas instituições de trabalho e de condições ambientais para a ordenha do leite, além da falta de creches próximas ou dentro do ambiente de trabalho, foram as principais dificuldades apontadas pelas mães em relação à manutenção da amamentação, o que justificaria os achados do presente estudo.

A partir do sexto mês, a alimentação complementar adequada deve ser iniciada como complemento ao aleitamento materno, com dietas variadas em consistência, caloria e nutriente. As práticas alimentares são influenciadas por diversos fatores, como o conhecimento, as vivências e as experiências construídas a partir de condições socioculturais e o saber científico de cada época $^{(24)}$.

Quando questionadas sobre a idade correta para iniciar alimentação complementar dos bebês, a maioria das mães da atual pesquisa referiu que o ideal seria introduzir inicialmente papas de frutas e legumes após o sexto mês do bebê. Outras mães, porém, relataram que fariam a introdução da alimentação complementar aos quatro meses. Os alimentos complementares devem ser ofertados após os seis meses de idade quando a criança já possui maturidade fisiológica para mastigar, deglutir e digerir. A introdução precoce da alimentação complementar contribui para a redução de absorção de ferro, presente no leite materno, podendo resultar em anemia nos bebês ${ }^{(19)}$.

Após os 6 meses de vida a criança deve receber 3 refeições por dia com alimentos complementares e incluir água nos intervalos das refeições. Essas refeições devem, inicialmente, ser compostas por duas papas doces e uma salgada, que pode incluir legumes e verduras, cereal ou tubérculo, alimento de origem animal e feijões. Aos 7 meses deve-se acrescentar mais uma papa salgada. Ao completar 8 meses, a criança pode passar a receber de forma gradual a alimentação preparada para a família, com uma quantidade de sal reduzida e excluindo-se temperos picantes e alimentos industrializados. Esses alimentos podem ser alterados em relação à consistência (triturados, amassados, desfiados ou cortados em pedaços pequenos) até a criança completar 1 ano, quando ela poderá receber os alimentos na consistência normal ${ }^{(8)}$.

Outro fator que chamou a atenção no estudo em questão é o relato das mães que acreditam que os bebês devem começar a receber alimentos complementares só ao completarem um ano de idade, ou que só devem ser ofertadas carnes após os 18 meses, apesar de ser uma minoria das mães entrevistadas. Esse atraso na introdução dos alimentos complementares pode ocasionar retardo do crescimento, risco de desnutrição e deficiência de micronutrientes, comprometendo o desenvolvimento adequado do bebê $\hat{e}^{(25)}$.

A intenção da introdução de alimentos industrializados, como iogurtes, papas industrializadas e outros alimentos lácteos na alimentação das crianças também foi um achado importante no presente estudo. Esse consumo pode ser influenciado por fatores como renda familiar, idade e escolaridade materna. Apesar de não existirem recomendações específicas com relação à quantidade e frequência do consumo de produtos industrializados, sabe-se que devem ser evitados, especialmente nos primeiros 
anos de vida. Isso se deve às evidências de que a ingestão continuada e excessiva promove o desenvolvimento precoce das doenças crônicas não transmissíveis ${ }^{(26)}$, como doenças cardiovasculares, diabetes, doenças respiratórias crônicas e câncer ${ }^{(27)}$.

Uma limitação do presente estudo deve-se à alta rotatividade das duplas mãe/bebê no alojamento conjunto. Dessa forma, a observação das mamadas foi realizada somente uma vez para cada binômio mãe/bebê. A observação de mais mamadas possivelmente poderia acarretar em escores diferentes, levando em consideração a curva da aprendizagem.

As dificuldades em relação ao aleitamento materno apresentadas pelas mães no presente estudo evidenciam a necessidade de profissionais capacitados (fonoaudiólogos, enfermeiros, médicos, nutricionistas) para realizar ações que auxiliem no inicio da amamentação, evitando o risco do desmame precoce, além de conscientização sobre introdução alimentar complementar adequada, visto que as mães apresentam falta ou conhecimento limitado a respeito do tema.

\section{CONCLUSÃO}

As mães investigadas possuem conhecimento limitado sobre amamentação e desconhecem os benefícios para a saúde da mulher, porém citaram benefícios em relação aos filhos. Além disso, a maioria das entrevistadas não sabe qual é o período recomendado para a realização do aleitamento materno exclusivo, embora soubessem que a introdução da alimentação complementar deva ser realizada após os 6 meses. Observou-se a presença de aspectos desfavoráveis no momento da amamentação. A presença de tecido mamário com escoriações associou-se com os comportamentos de sucções rápidas com estalidos, lábio inferior virado para dentro e à situação em que o bebê não mantém a pega da aréola, indicando uma pega incorreta e dificultando a amamentação.

\section{REFERÊNCIAS}

1. Medeiros AMC, Batista BG, Barreto IDC. Breastfeeding and speech-language pathology: knowledge and acceptance of nursing mothers of a maternity. Audiol Commun Rev. 2015;20(3):183-90.

2. Marques MCF, Melo AM. Amamentação no alojamento conjunto. Rev Cefac. 2008;10(2):261-71.

3. Silva MA, Farias MCAD, Sousa AKA, Abreu RMSX. Atuação da enfermagem em alojamento conjunto: percepção de puérperas. REBES. 2015;5(2):35-44.

4. Jesus ALBC. Influências dos fatores maternos e práticas de aleitamento materno no ingurgitamento mamário [dissertação]. Coimbra: Escola Superior de Enfermagem; 2013.

5. Carvalhães MABL, Corrêa CRH. Identificação de dificuldades no inicio do aleitamento materno mediante aplicação de protocolo. J Pediatr. 2003;79(1):13-20.

6. Azevedo ARR, Alves VH, Souza RMP, Rodrigues DP, Branco MBLR, Cruz AFN. O manejo clínico da amamentação: saberes dos enfermeiros. Esc Anna Nery Rev Enferm. 2015;19(3):439-45.

7. Corrêa EN, Corso ACT, Moreira EAM, Kazapi IA. Alimentação complementar e características maternas de crianças menores de dois anos de idade em Florianópolis (SC). Rev Paul Pediatr. 2009;27(3):258-64.

8. Ministério da Saúde (BR). Dez passos para alimentação saudável. 2a ed. Brasília: Ministério da Saúde; 2013 [acesso em 2017 abr 4]. Disponível em: http://www.blog.saude.gov.br/images/arquivos/dez_passos_alimentacao_saudavel_guia.pdf

9. Instituto Brasileiro de Geografia e Estatística. Pesquisa nacional de saúde 2013: ciclos de vida. Brasil e grandes regiões. Rio de Janeiro: IBGE; 2015.

10. Rodrigues AP, Padoin SMM, Guido LA, Lopes LFD. Fatores do pré-natal e puerpério que interferem na autoeficácia em amamentação. Esc Anna Nery Rev Enferm. 2014;18(2):251-67.

11. Santana JM, Brito SM, Santos DB. Amamentação: conhecimento e prática de gestantes. Mundo Saúde. 2013;37(3):259-67.

12. Brasil. Portaria ${ }^{\circ} 1.067$, de 4 de julho de 2005. Polítca Nacional de atenção à Saúde Obstétrica e Neonatal. Diário Oficial da República Federativa do Brasil, Brasília, 2005.

13. Escarce AG, Araújo NG, Friche AAL, Motta AR. Influência da orientação sobre aleitamento materno no comportamento das usuárias de um hospital universitário. Rev Cefac. 2013;15(6):1570-82.

14. Leite RFB, Muniz MCMC, Andrade ISN. Conhecimento materno sobre Fonoaudiologia e amamentação em alojamento conjunto. Rev Bras Promoç Saúde. 2009;22(1):36-40.

15. Martins RMC, Montrone AVG. Implementação da Iniciativa Unidade Básica Amiga da Amamentação: educação continuada e prática profissional. Rev Eletrônica Enferm. 2009;11(3):545-53. 
16. Demitto MO, Silva TC, Páschoa ARZ, Mathias TAF, Bercini LO. Orientações sobre amamentação na assistência pré-natal: uma revisão integrativa. Rev Rene. 2010;11:223-9.

17. Carvalho ACO, Saraiva ARB, Gonçalves GAA, Soares JR, Pinto SL. Aleitamento materno: promovendo o cuidar no alojamento conjunto. Rev Rene. 2013;14(2):241-51.

18. Benabou S, Duran ECM, Vale IN. Avaliação da técnica de amamentação em alojamento conjunto de um hospital universitário. Rev Enferm UFPE. 2012;6(11):2735-43.

19. Schincaglia RM, Oliveira AC, Sousa LM, Martins KA. Práticas alimentares e fatores associados à introdução precoce da alimentação complementar em crianças menores de 6 meses na região noroeste de Goiânia. Epidemiol Serv Saúde. 2015;24(3):465-74.

20. Amaral LJX, Sales SS, Carvalho DPSGP, Cruz GKP, Azevedo IS, Ferreira MA Júnior. Fatores que influenciam na interrupção do aleitamento materno exclusivo em nutrizes. Rev Gaúch Enferm. 2015; 35(Esp):127-34.

21. Frota MA, Mamede ALS, Vieira LJES, Albuquerque CM, Martins MC. Práticas culturais sobre aleitamento materno entre famílias cadastradas em um programa de Saúde da Família. Rev Esc Enferm USP. 2009;43(4):895-901.

22. Xavier BS, Nobre RG, Azevedo DV. Amamentação: conhecimento e experiência de gestantes. Nutrire. 2015;40(3):270-7.

23. Melo MCP, Luna ICF, Gomes AIR, Bastos LDM, Bringel NMM. Aleitamento materno e suas particularidades: uma abordagem teórico-prática sobre o tema. Enciclopédia Biosfera. 2010;6(11):1-11.

24. Vendruscolo JF, Bolzan GM, Crestani AH, Souza APR, Moraes AB. A relação entre aleitamento materno e transição alimentar e os indicadores de risco para o desenvolvimento infantil. Disturb Comun. 2012;24(1):41-52.

25. Cunha LEO, Soares AED, Costa GA, Lessa NMV. As desvantagens da introdução alimentar precoce e/ou tardia de alimentos complementares. In: Anais do $3^{\circ}$ Congresso de Ciências da Saúde, $12^{\circ}$ Semana de iniciação Científia e $3^{\circ}$ Semana de Extensão; Coronel Fabriciano. Minas Gerais: UNILESTE/MG; 2011.

26. Toloni MHA, Silva GL, Goulart RMM, Taddei JAAC. Alimentação nos primeiros anos de vida: o advento dos alimentos industrializados. Pediatr Mod. 2014;50(4):155-61.

27. Duncan BB, Chor D, Aquino EML, Bensenor IM, Mill JG, Schmitd MI, et al. Doenças crônicas não transmissíveis no Brasil: prioridade para enfrentamento e investigação. Rev Saúde Pública. 2012;46(Supl 1):126-34.

\section{Endereço do primeiro autor:}

Juliana de Brito de Souza Rosa

Universidade Luterana do Brasil - ULBRA

Av. Farroupilha, 8001

Bairro: São José

CEP 92425-900 - Canoas - RS - Brasil

E-mail: fga.julianabrito@gmai.com

\section{Endereço para correspondência:}

Susana Elena Delgado

Universidade Luterana do Brasil - ULBRA

Av. Farroupilha, 8001

Bairro: São José

CEP 92425-900 - Canoas - RS - Brasil

E-mail: sudel.ez@terra.com.br 